\title{
A questão étnico-racial no Brasil contemporâneo: notas sobre a contribuição da teoria das representações sociais ${ }^{1}$
}

\author{
The ethnic and racial issues in contemporary Brazil: comments on the contribution of \\ the social representation theory \\ Elisabete Figueroa dos Santos ${ }^{2}$ \\ Rosemeire Aparecida Scopinho ${ }^{3}$
}

\begin{abstract}
RESUMO: As reflexões propostas neste artigo buscaram evidenciar a participação das representações sociais na construção do racismo e discutir o seu papel na produção de alteridades e identidades. Tomamos como referência o contexto social brasileiro, onde o debate étnico-racial foi ampliado nas últimas décadas, mas no qual há ainda um quadro incipiente de formulações analíticas consensuais no campo acadêmico, assim como de proposições inclusivas no campo das políticas públicas que avancem para além das cotas ou reserva de vagas. Diante deste cenário, pontuamos que o referencial da Teoria das Representações Sociais é oportuno para possibilitar o conhecimento dos diferentes universos que transitam pelos mesmos espaços, por vezes de maneira desigual, e disputam a esfera pública. Salienta-se a necessidade de avançar na agenda de ações programáticas coerentes com as realidades e demandas dos diferentes segmentos sociais, por meio de planejamentos a curto, médio e longo prazos para que as representações sociais atravessadas pelo racismo sejam deslocadas, estereótipos sejam superados e novos significados sejam atribuídos às identidades de brancos e negros no Brasil.
\end{abstract}

Palavras-chave: representações sociais; raça; racismo; alteridade; ações afirmativas.

\begin{abstract}
The present essay tries to evidence the participation of social representations in the construction of racism and to discuss their role in the production of otherness and identity. The Brazilian social context has been taken as reference, where the ethnic and racial debate has grown within the last two decades, but in which there is still an incipient presence of consensual academic analysis, as well as a lack of inclusive propositions in public policies that could go beyond quotas or vacancy reserve. By observing this scenario, we clarify that the SRT (Social Representation Theory) is useful in order to make possible the acknowledgement of the different realities which may transit within the same spots, sometimes unequally, and dispute the public spheres. Here we highlight the need for going further in the agenda of coherent pragmatic actions and demands from diverse social segments, by planning short, mid and long term so that the social representations traversed by racism can be put aside, stereotypes can be overcome and new challenges can be put to the identity of black and white people in Brazil. Keywords: social representation; race; racism; otherness; affirmative actions.
\end{abstract}

As configurações da dinâmica das relações raciais no Brasil desde o período da escravização dos africanos têm demandado esforços, ferramentas e elaborações analíticas diversas, de modo a constituírem-se arcabouços e agendas específicas das várias áreas do conhecimento, dentre elas a Psicologia. Resguardadas possíveis particularidades teóricas e epistemológicas, no campo da Psicologia é possível identificar vieses e centralidades na abordagem da temática racial através do tempo e do espaço.

\footnotetext{
${ }^{1}$ As autoras agradecem à Fapesp - Fundação de Amparo à Pesquisa do Estado de São Paulo.

2 Doutora em Psicologia pela Universidade Federal de São Carlos (UFSCar); Professora do Instituto Superior de Educação do Vale do Juruena - Juína, MT, Brasil. E-mail: bete.figueroa@gmail.com.

3 Professora Associada do Departamento de Psicologia, Programa de Pós-Graduação em Psicologia e Programa de PósGraduação em Sociologia da Universidade Federal de São Carlos - São Carlos, SP, Brasil.
} 
Parcela desta complexidade analítica foi alvo de estudos de Santos, Schucman e Martins (2012). Com o propósito de examinar o tratamento que a Psicologia tem dado ao estudo da temática étnico-racial no Brasil, estes pesquisadores traçaram uma linha no tempo em que propõem três momentos do pensamento psicológico brasileiro, delimitados a partir de tendências moldadas por rupturas e constituição de novos saberes, cujas orientações preponderantes foram de ordens biológico-causal, culturalista e relacional. Conforme apontam os autores, primeiramente, em fins do século XIX e início do século XX é possível localizar estudos pautados, basicamente, pelo objetivo de traçar as características psicológicas dos escravos e ex-escravos, tendo-se em vista fornecer elementos para a demarcação do negro como sujeito psicológico. Esta agenda configura a chamada "Escola Nina Rodrigues". O período de 1930 até 1950, por sua vez, é caracterizado pelo debate da construção social e cultural das diferenças, de modo a predominar um viés de desconstrução do determinismo biológico das raças. Por fim, a partir de 1990, vigoram os estudos sobre branqueamento e branquitude, tendo como principais referências Jurandir Freire Costa, Irai Carone, Maria Aparecida da Silva Bento e Edith Pizza. Nesse interim, além de debates e ações de promoção da igualdade étnico-racial, o foco está em discutir criticamente o legado social do branqueamento e seus efeitos psicológicos sobre a identidade étnico-racial de negras e negros, ao mesmo tempo em que se traz à tona as formas e manifestações da identidade branca, denominada branquitude. Não se deve, contudo, perder de vista que entre estes períodos constatam-se momentos de reticências e silenciamentos da Psicologia em relação à temática, indicando resistências e/ou dificuldades em dar seguimento a esta pauta.

Martins, Santos e Colosso (2013) apresentaram um panorama de como as relações étnico-raciais têm sido tratadas pela Psicologia no Brasil, a partir da análise de artigos publicados em periódicos nacionais de Psicologia, no período de 2000 a 2009. O exame dos 41 artigos identificados apontou que esta produção esteve centrada em discutir a violência psicológica do preconceito e do racismo; o legado social do branqueamento e seus efeitos psicossociais sobre a identidade étnico-racial de negros e brancos; e o monitoramento dos efeitos das políticas e dos programas de promoção da igualdade étnico-racial. Torna-se evidente que as relações raciais têm sido objeto de investigação da Psicologia, particularmente da Psicologia Social, e que a noção de raça, paulatinamente, é dimensionada pelos(as) pesquisadores(as) deste campo como categoria de análise para compreensão das diferenças, discriminações e desigualdades sociais.

Uma vez que a Psicologia e sobretudo a Psicologia Social, tem voltado sua atenção para as implicações da categoria raça e empreendido esforços para produzir conhecimento em relação à temática, caberia questionar: por que problematizar as questões raciais a partir do aporte da Teoria das Representações Sociais (TRS)?

Diversas podem ser as respostas elencadas, mas iremos nos centrar em duas. Primeiramente, é de suma importância situar o momento em que se encontram atualmente as relações étnico-raciais no Brasil, demonstrando a que construções sociais e históricas estas respondem.

Particularidades sociais e culturais são verificadas na forma como as relações entre diferentes grupos raciais foram instaladas no Brasil. Aqui, não se perceberam regulamentações oficiais que explicitassem regimes separatistas com base em critérios raciais, ao contrário: buscou-se estrategicamente agregar ao imaginário social brasileiro a noção de que em terras tupiniquins era vigente uma ampla democracia racial. As relações 
sempre foram, portanto, perpassadas pela dimensão concreta da convivência e da proximidade entre as diferenças em muitos espaços e no cotidiano. A característica da convivência permitiu a construção de sentidos que vincularam a experiência de proximidade à ideia de harmonia entre as raças.

Diante de um cenário em que se notam discursos que apregoam a existência de um paraíso racial brasileiro e estudos de indicadores sociais que demonstram que a fenda existente entre brancos e negros apresenta padrões muito similares ao de países em que foram vigentes sistemas oficiais de segregação racial (Soares, 2000; Henriques, 2001; Campante, Crespo \& Leite, 2004; Paixão \& Carvano, 2008; entre outros), o movimento negro irrompe o debate denunciando a falácia do mito da democracia racial e empreendendo organizações e estratégias para divulgar e levar a cabo suas demandas por políticas efetivas que interviessem neste quadro de desigualdades em favor de negras e negros. Eclodem, portanto, no cenário nacional, projetos de implementação de medidas afirmativas para a população negra, principalmente no ensino superior e no mercado de trabalho.

Conforme apontamos anteriormente (Santos, 2011a), a proposição e efetivação de políticas afirmativas para negros no ensino superior rompem definitivamente 0 silenciamento sobre a dinâmica racial no Brasil. As relações que se pretendiam harmoniosas são deflagradas e tensionadas de modo a compor-se uma arena de debates sobre as práticas de discriminação racial e a necessidade e viabilidade de políticas públicas voltadas à estimulação da inserção de negros e negras em lugares estratégicos da sociedade. Essa pauta convoca os grupos sociais implicados a posicionarem-se sobre tal rearranjo. O sistema relativamente estável de representações sobre raça, discriminações e privilégios é colocado em causa. São suscitadas representações sociais para situar os sujeitos sobre o quadro de não-familiaridades que se conforma, sobretudo em meio à recente confirmação legal de políticas afirmativas tanto pelo debate ocorrido no âmbito do Supremo Tribunal Federal (STF) quanto pela promulgação da Lei de Cotas para o acesso ao Ensino Superior (Brasil, 2012) e das leis sancionadas para instituição de cotas raciais no serviço público federal (Brasil, 2014) assim como na capital do estado mais rico do Brasil (São Paulo, 2013), entre outras localidades.

Este debate sobre ações afirmativas avulta no seio social a elaboração de discursos favoráveis e contrários às medidas afirmativas, especialmente àquelas voltadas à população negra. As diferentes perspectivas podem ser identificadas tanto no interior dos discursos produzidos pelos movimentos negros e nas discussões e produções acadêmicas, quanto na ampla sociedade. Entendemos que as diferentes representações que estão aí em disputa ancoram-se em modos divergentes de situar as relações raciais no Brasil, seus impactos e resultantes. Essas representações vinculam-se diretamente às formas de entendimento do papel do racismo nas trajetórias de brancas/brancos e negras/negros, bem como às identidades daqueles que representam.

Neste contexto, em que a tese da democracia racial, tão exaltada em nossa sociedade é, definitivamente, colocada em xeque, surgem outros discursos e representações e o debate racial na esfera pública ganha novos contornos. A TRS apresenta-se como importante recurso teórico para apreender e analisar as dissonâncias, os consensos e dissensos engendrados nas ações societais dos grupos mobilizados e nas transformações sociais que se solicitam e/ou se anunciam. 
Além da argumentação até então desenvolvida para justificar o presente artigo, cabe ainda colocar em debate as características que via de regra se tem verificado nos estudos sobre a temática racial que fazem uso do referencial da TRS. De maneira geral, eles valem-se dos recursos metodológicos fornecidos pela teoria; buscam situar as representações acerca de um objeto/tema específico entre diferentes grupos sociais; e/ou, muitas vezes, englobam "raça" como uma das variáveis a serem consideradas na pertença dos sujeitos que tecem representações sobre um objeto específico (Cabecinhas \& Amâncio, 2003; Pereira, Torres \& Almeida, 2003; Ferreira \& Mattos, 2007; Menin, Shimizu, Silva, Cioldi \& Buschini, 2008; Naiff, Naiff \& Souza, 2009; Lage, 2003; Sacramento \& Nascimento, 2011; entre outros). Contudo, pouco tem sido dito acerca de como as representações sociais e os seus mecanismos de construção participam da dinâmica das relações raciais no Brasil. Isto é, o que apontamos é que o potencial da TRS tem sido pouco explorado para traduzir os fenômenos sociais implicados na esfera do racismo em conceitos e noções teóricas que contribuam para compreender como, historicamente, têm se dado as relações raciais no contexto brasileiro.

Valentim (2013) aponta que os usos da Teoria das Representações Sociais têm crescido nos países da América Latina, incluindo o Brasil, contrariamente ao que se tem observado na Europa. No entanto, conforme salienta o autor, o aumento no corpo de estudos produzidos não necessariamente indica ou é acompanhado de avanços ou aprofundamentos teóricos:

\begin{abstract}
Desde logo, uma certa ligeireza, ou mesmo fraquezas teóricas que, não raramente, caracterizam este tipo de estudos. A noção de RS aplica-se a tudo e, aparentemente, dispensa reflexão teórica sólida. Assim, vai-se multiplicando pesquisa empírica sem grandes exigências de trabalho teórico prévio. Em vez de um aprofundamento teórico, de um diálogo e articulação com outras teorias (e até disciplinas adjacentes), ficamos, com uma frequência demasiado excessiva, no quadro de ideias vagas, genéricas e imprecisas. As RS passam a moldura explicativa, alimentada por uma espécie de portfolio da objectivação, em que perguntamos às pessoas "o que é para si... (não importa o quê)? ". Juntamos de algum modo as respostas que as pessoas nos dão, e eis-nos com um novo estudo sobre RS. Esta facilidade faz, demasiadas vezes, dos estudos em RS uma espécie de grounded theory ingénua alimentada pelo registo de teorias do senso comum. O que é, por si só, seriamente comprometedor do futuro das representações sociais (p. 161).
\end{abstract}

A partir de tais considerações, este artigo tem por intuito realizar uma reflexão teórica sobre a atuação das representações sociais na produção de identidade e alteridade, tendo como referência empírica a dinâmica das relações raciais no Brasil. As considerações apresentadas derivam de debates realizados no percurso de pesquisas realizadas em nível

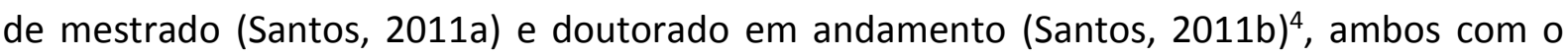
aporte teórico e metodológico da TRS. Buscamos, primeiramente, articular as noções de representações sociais, identidade, alteridade e raça e a seguir discutimos como estas articulações estão embasadas pelo medo do contato com a estranheza/não-familiaridade. Esperamos que esta reflexão contribua para ampliar o horizonte de problematização das relações raciais dentro do escopo da TRS.

\title{
Representações sociais: identidade, alteridade e raça
}

A relevância de certo objeto para um sujeito e para o seu grupo social é fundamental para que seja empreendida uma representação social acerca daquele objeto, de modo a questionar-se os recortes e fendas do real e, por esta via, edificar um mundo compreensível

\footnotetext{
${ }^{4}$ Pesquisas realizadas sob a supervisão da Profa. Dra. Rosemeire Aparecida Scopinho e com apoio financeiro da Fundação de Amparo à Pesquisa do Estado de São Paulo (FAPESP).
} 
para ambos (objeto e sujeito/grupo). De acordo com Moscovici (1978), a representação social é uma das atividades psicossociais por meio das quais os homens tornam inteligível a realidade física e social, inserindo-se num grupo ou numa ligação cotidiana de trocas. As representações são, assim, mecanismos pelos quais os grupos sociais apreendem questões do mundo externo, cuja relevância esteja implicada diretamente às suas dinâmicas, ao passo que edificam este mesmo mundo. Logo, à medida que os sujeitos representam determinado objeto, é traçada uma interpretação individual, em um processo que é autônomo, mas também relacional, cuja origem está nas diversas inscrições sociais que compõem estes sujeitos.

A autonomia para tecer representações não está ligada a projetos solipsistas, mas a várias ordens de representações sociais que compõem cada um dos sujeitos, advindas das suas diversas inscrições sociais. Quando alguém se manifesta é, concomitantemente, interpelado pelas representações e discursos de seus grupos sociais de pertença, por argumentos contrários, pelas elaborações midiáticas, enfim, por diferentes instâncias que o arguem sobre o objeto em questão. Assim, quando alguém exprime uma opinião sobre determinado objeto é porque já (se) representou algo sobre ele.

Ao contrário da premissa que preconiza que dado objeto do mundo atua como estímulo e, portanto, solicita uma resposta do sujeito, a TRS propõe que não é qualquer objeto que solicita uma representação. Ou seja, a representação do objeto está na origem e na importância que o próprio objeto tem para o sujeito. São as posições assumidas pelo sujeito, suas inscrições e formas de dialogar com o meio social que dizem se certo objeto lhe é relevante ou não. Para ser relevante é necessário que o sujeito se represente no objeto. Logo, nesta relação, sujeito e mundo são socialmente constituídos por meio das representações.

Para Moscovici (2007) representações sociais são solicitadas dentro das estruturas representacionais da própria cultura, por exemplo, na tensão entre o reconhecimento formal da universalidade dos "direitos do homem", e a sua negação a grupos sociais específicos dentro da sociedade, como é o caso dos negros.

Na sociedade brasileira, a dinâmica de exclusão/inclusão social caracteriza uma fenda existente, que dificulta que o grupo negro se aproprie e goze, plenamente, dos direitos de cidadania. São essas clivagens sociais que proporcionam a ocasião para que se engendrem as representações sociais. A ausência de sentido verificada nesses pontos de cisão traz à tona a não-familiaridade do excluído. Os sujeitos, então, tecem representações visando empreender sentidos e significados à "estranheza" que se apresenta (Moscovici, 1978).

Como diz Jodelet (2001), da mesma forma como a natureza não aprecia o vácuo, também a cultura não é afeita à ausência de sentido. Desse modo, são construídas representações para familiarizar o não-familiar e, assim, restabelecer um sentido de estabilidade.

Os grupos socialmente hegemônicos produzem e veiculam discursos constituintes e construtores de representações sociais que desqualificam e desvalorizam o diferente (Guareschi, 2011). Para o grupo dominante branco, o negro constitui um sujeito cujas características físicas e culturais fogem daquilo que "deveriam" ser, uma vez que diferem enormemente da "norma" branca. Assim, com o intuito de "familiarizar" a não-familiaridade negra, o grupo hegemônico constrói representações sociais que, de um lado, desqualificam o negro, e de outro buscam assimilá-lo, o que pode levar os negros a representarem-se e 
identificarem-se como brancos para serem socialmente aceitos. Pode-se dizer que o negro brasileiro se encontra numa situação de clivagem social e simbólica: apesar desta ocorrência não ser suportada por meios oficiais explícitos, verifica-se que os negros se encontram à margem da sociedade, num processo de prejuízo social.

Faceta crítica desta organização racial desigual foi expressa por meio de uma ideologia de branqueamento, cuja atuação é pautada na eliminação simbólica do negro, o outro. Por meio da determinação de um padrão social branco eurocêntrico a ser perseguido, é estabelecido quem deve ser sujeito de direitos e privilégios sociais ou não, exaltando características brancas e inferiorizando aquilo que remeta a não-brancos. Dada a difusão dessa ideologia na mídia, nas práticas sociais e nos comportamentos cotidianos, muitos negros veem-se por ela tomados, o que afeta sua identidade racial e pode levá-los à adesão de valores e práticas eurocêntricas.

As circunstâncias socioeconômicas e educacionais vivenciadas pelos negros, marcadas que são pela desigualdade, são causa para contínuo esforço de familiarização, adaptação e enfrentamento às situações de exclusão, inclusão precária e marginalização. Acerca das razões e formas organizativas que a partir de critérios étnicos e/ou raciais tensionam o processo de identificação dos sujeitos, nos fala Jodelet (2001):

\footnotetext{
É claro que hoje, nas sociedades onde as posições e conflitos multiétnicos e multiculturais estão exacerbados, se observa que as afirmações e as defesas identitárias dos diferentes "nós" obedecem a processos semelhantes e complementares, engendrando a espiral dos racismos diferencialistas e afugentando a utopia do universalismo abstrato e da razão igualitária. $\mathrm{Na}$ leitura destes choques, onde se forjam os nós secundários (...) as ciências sociais se repartem para ver neles um reforço das identidades comunitárias, salutares para os indivíduos, ou para revelar os riscos das opressões ou desordens mortíferas. Contudo, pouco ainda foi dito sobre a experiência vivida pelos que estão expostos à situação de alteridade, e sobre a exclusão que resulta dela (Jodelet, 2001, p. 65).
}

Para a autora, colocar em perspectiva as relações com o outro, a pertença social e a sua tradução nas manifestações concretas da vida e da produção social abre caminho para a aproximação à alteridade radical. Esta última encontra sua expressão extrema no racismo, cujas manifestações encadeiam ao mesmo tempo práticas e discursos e suscitam representações, teorização e organização dos afetos. Figuram no quadro das práticas as diferentes formas de violência, desprezo, intolerância, humilhação, exclusão; os discursos veiculam representações e teorias (Jodelet, 1998). Dessa forma, é dada a dificuldade para o negro estabelecer uma identidade negra positiva, uma vez que ele é socialmente construído como o outro, no qual são projetados elementos negativos.

Tendo-se em vista os processos práticos e simbólicos de marginalização, pode-se situar a alteridade como forma específica de relação social, indo além de colocações coisificantes que imputam ao outro a tarefa de negar o mesmo. A formulação da alteridade radical articula representações e práticas. Essas construções se dão por relações sociais marcadas seja pela exclusão - que pode ir, segundo Jodelet (2001), até o extermínio numa perspectiva de proteção contra a "contaminação"; de purificação - seja pela opressão, a exploração, numa perspectiva de inserção hierarquizada e subordinação social. As representações sociais são a amálgama que propicia a unidade dos processos de elaboração e exclusão social que estão na base da formação da alteridade.

Para além da compreensão de um objeto particular, as representações sociais emergem como "forma em que o sujeito (indivíduo ou grupo) adquire uma capacidade de 
definição, uma função de identidade, que é uma das maneiras pelas quais as representações expressam seu valor simbólico" (Duveen, 2004, p. 21). Em síntese, representações são construções simbólicas sempre ligadas ao lugar a partir do qual os sujeitos representam, estando, portanto, intimamente determinadas por identidades, interesses e lugares sociais (Jovchelovitch, 1998).

No Brasil, a berlinda identitária para o negro torna-se mais evidente nos lugares sociais mais visados ou de maior prestígio, como é o caso do ensino superior público e do mercado de trabalho. $O$ acesso ao ensino superior público tem sido, ao longo dos tempos, privilégio das elites brancas deste país. A educação básica, fundamental e média em qualidade mais elevada proporciona maior probabilidade de acessar o ensino superior público, os cursos mais concorridos e de maior prestígio, o que, por sua vez, aumenta a capacidade de acessar as melhores colocações no mercado de trabalho. Questões que têm, tradicionalmente, sido mais frequentes na vida de brancas e brancos.

Para melhor analisarmos o fenômeno social do racismo, seus arranjos, práticas e formas de atuação, cabe ponderarmos sobre a proposição de Jodelet (2001) que opõe, de um lado, de um "racismo autorreferencial", cujos termos estabelecem a superioridade hierárquica do racista - que é detentor de poder - e, de outro, um "racismo heterorreferencial" ou "heterofóbico", que localiza as características da vítima num lugar de inferioridade.

No entanto, entendendo o racismo como processo edificado por meio da elaboração de representações sociais, podemos julgar que se tratam de construções auto e heterorreferenciais, ou seja, o racismo edifica as identidades de brancos e negros, posto que, para que um objeto seja representado, ele é comparado a vários outros de uma mesma ordem dentro de uma escala de valores. Ao comparar e hierarquizar, incorre-se num processo de alocação/construção de todos os elementos que compõem uma mesma ordem de comparação, simultaneamente. Logo, ao definir alguém como negro é feita a afirmação de que este não é branco, indígena, asiático etc. É posta a dialética identidade-alteridade.

Essas elaborações e orientações de conduta organizam os afetos. O auge de sua manifestação obsessiva resulta na construção de estereótipos que edificam tanto os alvos quanto os agentes do racismo (Jodelet, 2001). Logo, os brancos, ao construírem os negros como alteridade radical, auto edificam-se como sujeitos por excelência; como duas faces da mesma moeda. É, portanto, imprescindível à Psicologia Social e às demais disciplinas que compõem as Ciências Sociais desvelarem o fato de que tanto brancos quanto negros têm suas subjetividades e identidades atravessadas pelo racismo.

\section{Do medo de ser tocado(a) pela situação de alteridade}

No contexto das relações sociais travadas com sujeitos que estejam sob a situação de alteridade, o medo de ser tocado por esta circunstância é flagrante. Neste sentido, o toque assume conotações divergentes. Por um lado, atribui-se o sentido de mácula. Há o temor de ser marcado, manchado pela circunstância da outridade, de modo a ser-lhe imputadas representações e significados que remetam ao não-sujeito social. Por outro, atrela-se o sentido de sensibilização. Busca-se proteger da possibilidade, ainda que remota, de ser compassivo a valores e características vinculados à não-familiaridade, o que demandaria esforços de desconstrução, novos acordos e negociações diante de seus grupos de pertença 
e demais interlocutores. Tais arranjos ancoram-se no desejo de manter-se alheio a toda forma de contágio e contaminação pela alteridade.

Sobre a experiência de termos contato e sermos interpelados por algo ou alguém cuja realidade e concretude insistimos em não perceber, ainda que tenhamos que conviver com este objeto/sujeito, Moscovici (2007) propõe que:

De fato, todas as coisas, tópicos ou pessoas banidas ou remotas, todos os que foram exilados das
fronteiras concretas de nosso universo possuem sempre características imaginárias; e pré-
ocupam e incomodam exatamente porque estão aqui, sem estar aqui; eles são percebidos, sem
ser percebidos; sua irrealidade se torna aparente quando nós estamos em sua presença; quando
sua realidade é imposta sobre nós. (Moscovici, 2007, p. 56).

Visando defender-se da ameaça da negritude, o branco elabora representações e práticas para "conter" a ameaça do outro, o negro. São produzidas representações pejorativas que são difundidas e veiculadas no e pelo grupo social dominante. Conforme demonstra André (2007), cerca de 50 milhões de africanos foram trazidos ao Brasil durante mais de 300 anos de escravidão, advindos principalmente das regiões de Angola, Moçambique, Cabo Verde e Guiné Bissau. Esses povos foram os primeiros a serem qualificados "negros inferiores". As construções a partir de tais ideias acerca do negro conferiram-Ihes uma posição ideologicamente constituída por estereótipos. As crenças apontavam para uma suposta inferioridade intelectual, emocional e social; ao passo que o negro representaria falta de moralidade, corrupção e morte, o branco seria signo de pureza, vida e moral.

Essas representações caracterizam-se por serem elaborações que remetem a um anseio de inspeção, sondagem e vigília. Articuladas em torno das marcas da diferença, operariam a função de, constantemente, evidenciar a necessidade de expurgar o corpo social; acastelar as próprias identidades além do alcance de toda forma de promiscuidade e mestiçagem, padrões circunscritos como riscos de invasão (Jodelet, 2005).

A partir das reflexões expostas, defendemos que a invisibilidade do negro na sociedade brasileira ganha novas formas quando são implantadas medidas afirmativas de cunho racial. É, então, que se passa a enxergar o negro; a realidade negra é posta, de forma desnuda, sobre os privilégios do grupo dominante. É neste contexto que todo o passado histórico se revela ainda atual. A pretensa harmonia representada na ideia de democracia racial é denunciada. Configura-se a discussão de forma explícita: no debate aberto, com as suas contradições escancaradas (Ferreira \& Mattos, 2007). Uns reivindicam a garantia de seus direitos e outros a garantia da permanência de seus privilégios, sob a forma abstrata da meritocracia.

Em pesquisa realizada anteriormente (Santos, 2011a), debruçamo-nos sobre o estudo das representações sociais elaboradas acerca das relações que se estabeleceriam entre negritude, educação e trabalho, a partir da realização de entrevistas semiestruturadas com estudantes universitários negros, ingressantes na Universidade Federal de São Carlos (UFSCar) nos três primeiros anos de implantação do Programa de Ações Afirmativas (2008 a 2010) - como adeptos da reserva de vagas ou não.

Dentre várias outras questões, os estudantes foram questionados sobre como era a convivência com os seus pares e professores. Selecionamos dois trechos de entrevistas que apresentam elementos importantes para ponderarmos acerca da dinâmica racial que se 
estabeleceu na Universidade após a implantação do Programa - contexto em que os conflitos raciais tendem a se tornar mais flagrantes, conforme é possível observar a seguir:

(...) Isso também é coisa da universidade... É...Trabalho em grupo: "Ah! Eu quero que vocês aprendam a trabalhar em grupo. Formem os grupos." É a pior coisa que existe! Porque quando ele fala "formem os grupos", é sempre o mesmo grupo que vai fazer. É sempre a mesma panela. Não tem essa mudança! Se você sempre está no mesmo grupo, você já sabe como é que o outro trabalha, como você trabalha... O problema é quando o professor diz em que grupo que você vai ficar. Não é? Daí é que a coisa complica, porque aí você tem que trabalhar com a diferença. Só que... É uma coisa assim... Da universidade e das próprias pessoas mesmo. Eu tenho muita dificuldade também. Eu não sei... Eu acho que eu sou um pouco antissocial... Porque...nenhum grupo me aceita. Eu sempre fico por último e... Assim, eu pergunto, sabe? Na hora que o professor já fala, eu: "Posso fazer com você? Posso fazer com você?" E daí a pessoa: "Ah, eu vou pensar ainda!" "Você já tem um grupo?" "Ai, já tenho." Mas, não tem ainda! Pronto. Daí, teve um grupo agora que, uma pessoa saiu. Ele se desfez. E eu entrei no lugar dessa pessoa, mas assim: por dó, sabe? Porque não tinha outro jeito. Aí na aula de Experimental, tinha certinho para formar duplas... Certinho! Mas, teve uma pessoa que entrou numa dupla. Ficaram três pessoas! Eu ainda perguntei: "Mas, professora, pode ficar três pessoas?" Ela falou: "Não." Mas, não tem problema. O importante é a pessoa não fazer comigo! Então, eu não sei o que é isso! Eu também não sou, assim, a pior pessoa do mundo para fazer dupla! E na Química, inclusive, eu vou muito bem, eu fecho com uma nota muito boa. Eu não sei... É um problema comigo, assim... Eu acho que eu ajudo nisso também. Porque eu não vou nas festas, eu não fico nas rodinhas conversando bobagem, conversando coisas tipo: "Ah, o Cálculo III, não sei quê"; "Porque a minha iniciação, não sei o quê..." Sabe? Coisas que são do mundo deles: "Ah, o meu carro... tive dois pontos na minha carta!" Sabe? Coisas que não fazem parte do meu mundo. Então, eu não fico nessas rodinhas, não é? Eu vou para o banheiro... Antes eu ficava, mas eu não tenho paciência. Aí, eu vou para o banheiro, fico... vou no LIG [Laboratório de Informática da Graduação] mais próximo. Tento sair. E, eu sempre sento na frente também, porque eu não enxergo direito e é mais fácil para eu me concentrar. Então, tem tudo isso, assim. Mas eu acho que o fato de eu ser negra influencia. Influencia muito, assim! Muito, muito... (chorando). Assim, é muito ruim, sabe? Porque... Antes de entrar aqui, eu não tinha noção de como era... Tão forte, assim. (Estudante de Engenharia Química) - Grifos nossos.

Querendo ou não dizer, as pessoas já te olham assim, por primeira parte... Tipo... Meio... Não sei. Eu senti muito preconceito na minha sala mesmo, sabe? Principalmente na hora de fazer aula em grupo, as pessoas só chamam aquele que é o perfil certo pra eles: $O$ que tem a roupa bonita, com aquela coisa de marca, aquele diálogo que só fala em festa... No meu grupo, estávamos eu mais um amigo meu e os dois índios! A gente não se segregou. A gente esperou que eles chamassem a gente para participar dos grupos. Poucos chamaram. Chamaram mesmo, aquelas pessoas mais humildes, que vieram do mesmo contexto histórico que eu e sabem a situação como que é. A maior parte da galera, até hoje mesmo, com o tempo que passou das aulas, a gente convivendo um pouco junto... Poucos passam perto, tipo, de mim mesmo e falam "oi", cumprimentam, ou chamam para ir para algum lugar. Olham meu estilo, pelo meu estilo de roupa; olham no modo de falar e olham nos livros que eu leio. Isso faz com que eles escolham se eles querem conversar comigo ou não. Mas mesmo pelo contexto de ser negro, eles já sentem. Às vezes dá para a gente chegar na sala e saber [que pensam ou dizem]: "Ai, deve ter entrado por cotas", "roubou a vaga do meu amigo..." Como aconteceu um caso comigo. Pensa essa coisa! Sabe? Já me senti muito incomodado na minha sala, já pensei em desistir do curso por causa disso. Mas isso vai ser em toda universidade, querendo ou não, eu vou ter que passar por isso... Para um dia isso não acontecer mais. (Estudante de Ciências Biológicas)

Ambas as falas enfatizam a questão da diferença. A estratégia utilizada pela maioria para lidar com as diferenças é a exclusão do diferente, das minorias, havendo, portanto, a negativa em lidar com ela, a saber: ser pobre e ser negro. Ambos os entrevistados, em determinados momentos, alegaram ser um problema que lhes era intrínseco, eles próprios eram a causa da rejeição. 
Todavia, o receio do que é estranho é o que assola tais relações. A ameaça de perder os marcos referenciais, de perder contato com o que propicia um sentido de continuidade, de compreensão mútua, é ameaça que tange o insuportável. E quando a alteridade é jogada sobre alguém, na forma de algo que "não é exatamente" como deveria ser, rejeita-se a possibilidade de aproximação e relação, pois se identifica aí uma ameaça à ordem estabelecida (Moscovici, 2007). É justamente o que se verifica nos casos apresentados. No anseio pela integração, a estudante de Engenharia Química afirmou que os grupos deveriam ser formados pelos professores, pois não sendo assim, ela continuaria a ser segregada pelos seus "companheiros" de turma. O medo da alteridade, de ser marcado, ou tocado pela diferença, é tal que no arranjo em que havia número adequado para a formação de duplas, conforme a prescrição de uma tarefa a ser realizada pela turma, uma pessoa integrou-se a uma dupla, formando um trio, e a entrevistada ficou sem parceria para executar a atividade.

Ambos os entrevistados, cujas narrativas estão transcritas acima, teceram variadas explicações para a exclusão que vivenciavam até, por fim, mencionarem o fato de serem negros. E aí apareceu a dor. A ferida de ser vítima de discriminação pelo fato de ser negro foi exposta. A primeira entrevistada inclusive chorou ao associar a segregação que vivenciava com a questão de ser negra. Para ambos, a ênfase na lástima de passar, cotidianamente, pela rejeição era evidente.

As diferenças de hábitos e de visão do papel da universidade entre os estudantes negros e a universidade como um todo são apontadas como uma circunstância que potencializa as dificuldades de relacionamento e, consequentemente, contribui para a discriminação desses estudantes. São mundos diferentes. Mundos que, por vezes, se interceptam, no tempo e no espaço, mas cujo estranhamento das relações não deixa de sinalizar e reiterar a diferença. São culturas, costumes, diálogos e objetivos distintos transitando no mesmo espaço. É explicitada a presença do outro, aquele que não é bem quisto, que é excluído.

Deste modo, a representação da universidade ancora-se no entendimento de ser este um território onde diferentes grupos raciais transitam, mas onde impera a supremacia dos brancos. Enquanto espaço em que predominam sujeitos, práticas e costumes brancos e elitistas, aquilo que foge à norma é afastado, é posto à margem.

A discussão acerca das ações afirmativas na Universidade estudada está implicada na percepção de racismo e discriminação. A associação imediata do negro a um ingressante por reserva de vaga é atrelada a uma prática de discriminação, tendo em vista que o que sustenta essa relação é a representação do negro como alguém incapaz de entrar na universidade por outras vias, o que situa a reversa de vagas como forma de "privilégio" concedido a não-brancos e não como instrumento utilizado a curto e médio prazos para garantir a entrada na universidade de contingentes historicamente discriminados. Esse quadro coopera para aumentar as dificuldades dos estudantes para assumirem-se como ingressantes pela reserva de vagas para negros.

\section{Das controvérsias em relação às ações afirmativas de cunho racial}

Estudos embasados na TRS têm apontado que as representações atribuídas às cotas raciais contestam a validade de políticas que utilizam raça como critério de seleção de seus beneficiários. Isto se deve, entre outros fatores, tanto à consideração de que estas medidas 
iriam ferir o "princípio de igualdade", quanto por haver a dificuldade de definição de quem é ou não de determinada raça. Neste contexto, flerta-se, sobremaneira, com as ideias assentadas na meritocracia (Ferreira \& Mattos, 2007; Neves \& Lima, 2007; Menin et al., 2008; Naiff, Naiff \& Souza, 2009; Santos, 2011a, Silva \& Silva, 2012). Além disso, haveria certa preocupação com a implosão de uma sociedade miscigenada e harmônica e a consequente construção de uma sociedade racializada. Sob essa perspectiva, as ações afirmativas de cunho racial seriam o palco para a instalação de conflitos raciais (Fry \& Maggie, 2004; Maggie \& Fry, 2004).

Essas representações ancoram-se em discursos intelectuais e acadêmicos que defendem um Brasil destituído de conflitos raciais e amplamente pautado numa atmosfera de misturas e convivência pacífica entre as raças (Freyre, 1966; Fry \& Maggie, 2004; Fry, 2005; Fry, 2005-2006; Maggie \& Fry, 2004; Maggie, 2005). Nessa ótica, as ações afirmativas culminariam na edificação de arenas de disputa, valendo-se, entre outras coisas, da prática dos "tribunais raciais", nos quais especialistas em raça seriam convocados a validar ou rechaçar a auto identificação dos candidatos, a exemplo do que foi desenvolvido na UnB (Fry \& Maggie, 2004; Maggie \& Fry, 2004).

Santos (2008) discute que as profetizações catastróficas disseminadas por intelectuais e demais contrários às cotas raciais estariam na ordem de terrorismos acadêmicos, cujas bases argumentativas expressariam mais o medo das problematizações e do contato com o outro (e, consequentemente, consigo mesmo) do que estimações com sólidas bases empíricas.

Cabe, portanto, questionar: as situações descritas nos relatos transcritos acima são conflitos gerados pelas ações afirmativas ou são, em verdade, a vasão e de sentimentos, representações e preconceitos que sempre estiveram latentes? Partilhamos da concepção de Lima, Neves e Silva (2014), segundo os quais:

(...) independentemente de resolverem ou não a flagrante desigualdade entre brancos e negros no nosso país, as políticas de ação afirmativa, com destaque para as cotas raciais, estimulam o debate sobre raça, racialização, justiça e racismo numa sociedade que sempre pareceu dormir no berço esplêndido do mito da democracia racial (p. 158).

Entendemos assim, que as ações afirmativas rompem com os acordos tácitos pelo abafamento das construções e significados que estão na base dos lugares sociais destinados aos diferentes grupos raciais.

\section{Considerações finais}

As representações sociais participam dos processos pelos quais se forjam e se situam identidades e alteridades. Elas demarcam, por meio da ancoragem, o status que o objeto representado ocupa e, por meio da objetivação dá forma aos conceitos. Em síntese, tecer uma representação social é dizer o que é identidade e o seu complemento, a alteridade.

Essa dinâmica torna-se problemática quando, ao delimitar o negro como alteridade radical, pelas vias do racismo, destina-se a este sujeito um lugar social marginal, caracterizado, no plano material, pela ausência de políticas de seguridade social, por direitos que não se efetivam e pela oferta de serviços de atenção social ineficientes; e, no plano simbólico, pelas inúmeras representações e significados negativos e desqualificantes que lhe são atribuídos. Essas duas esferas, ao mesmo tempo em que determinam a existência do 
racismo, retroalimentam esta mesma existência. São pontos chave para a discussão da problemática racial em países multirraciais (Santos, 2011a).

O fato é que as representações sociais são atravessadas por preconceitos e crenças fecundamente instaladas e ritualizadas ao longo dos tempos (Moscovici, 2007). Durante os cinco séculos de Brasil, o racismo se instaurou, se reinventou, se camuflou, se metamorfoseou e sobreviveu. Sua vivacidade é detectada e denunciada por diagnósticos críticos tanto por parte da academia quanto dos movimentos sociais, atualmente. Mas, seu horizonte de superação é ainda tímido.

Com base em crenças e vieses pré-existentes a um pensamento deliberado e proposital, as representações, impregnadas que são por essa atmosfera, edificam nossa realidade. Tratam-se de mecanismos prescritivos e relativamente estáveis que definem o negro com base em uma série de estereótipos e o convocam a agir e identificar-se como tal. Diante deste quadro, mesmo quando há alguma divergência em relação ao modelo imposto, convocamos determinada pessoa a enquadrar-se em tal categoria sob a pena de não ser compreendida ou codificada (Moscovici, 2007).

Mobilizar este sistema de representações não é tarefa fácil. Isto requer que sejam forjadas fortes "provocações" para abalar as estruturas arraigadas, como é o caso das Ações Afirmativas, cuja atuação problematiza as desigualdades e aponta para a reorganização dos espaços, lugares e direitos sociais.

Portanto, propostas eficazes e eficientes de enfrentamento do racismo devem ir além do mero combate aos signos brancos. É necessário ir à estrutura profunda, onde formam-se preconceitos e estereótipos que balizam representações sociais (Bernd, 1987).

Sendo as identidades e subjetividades de negras e negros perpassadas por estes estereótipos negativos, cabe questionar: é a mudança de sentidos quanto ao negro, sua cultura e lugares a ele atrelados suficiente para dissolver tal realidade social convencionada e prescritiva? Acreditamos que esta é apenas a "ponta do iceberg" de uma ação social que deve ser programática e organizada a curto, médio e longo prazos, para que as representações sociais se desloquem, os estereótipos dissolvam-se e novos significados sejam atribuídos às identidades de brancos e negros no Brasil.

Neste sentido, como oportunamente pontua Jodelet (2001), tanto o negro quanto a mulher foram, historicamente, construídos por representações marcadas pela violência simbólica e por um conjunto de exclusões. Ambos, porém, lutaram e lutam para não serem reduzidos a tais representações. Nestes casos, é imprescindível distinguirmos objeto e representação, pois é na pluralidade dos processos representacionais que reside a possibilidade de manter o objeto disponível para as tentativas constantes de atribuição de novos significados. Produzir contrarrepresentações, outras representações, que não reduzam a objetividade da condição negra e feminina às tentativas de construí-la socialmente como negativa tem sido parte da luta dos movimentos sociais dos negros e do movimento de mulheres.

Diante deste contexto, o referencial da TRS é oportuno para possibilitar o conhecimento dos diferentes universos que transitam pelos mesmos espaços, por vezes de maneira desigual, e disputam a esfera pública. A TRS permite elucidar a experiência de transitar o perímetro da exclusão e da marginalização; de ser banido das relações e trocas sociais. Por outro lado, este aporte admite pensar e planejar formas de intervenção, como 
políticas públicas, voltadas para suprir as demandas específicas dos diferentes segmentos da população.

Sendo assim, entende-se que as ações afirmativas acenam com a possibilidade de superação do racismo institucional por procurar garantir o direito de acesso à universidade de grupos antes, praticamente, ausentes neste espaço. No campo das relações sociais, no entanto, as manifestações tendem a traçar caminhos opostos e de conformação concomitante. De um lado, é possível que a convivência com a diferença ocasione a familiarização e positivação do contato entre os diferentes grupos raciais. De outro, é preciso também considerar a possibilidade de recrudescimento do racismo em algumas circunstâncias, conforme dão indícios os relatos apresentados na seção anterior.

Salientamos, todavia, que sendo o Brasil um país caracterizado pela diversidade de culturas e arranjos sociais, é importante pontuar que as falas transcritas neste artigo esboçam a realidade particular de um contexto de pesquisa, a saber: primeiros anos de implantação de ações afirmativas numa universidade federal do interior do Estado de São Paulo, de modo que em outros programas e outras localidades outras podem ser as realidades verificadas.

As reflexões propostas neste artigo buscaram evidenciar a parte que cabe às representações sociais na construção do fenômeno racista e discutir o seu papel na produção da alteridade e da identidade, tendo como referência o contexto social brasileiro, onde o debate ampliou-se nas últimas décadas, mas no qual ainda encontra-se um quadro incipiente de formulações analíticas consensuais no campo acadêmico, assim como de proposições inclusivas no campo das políticas públicas que avancem para além das cotas ou reservas de vagas.

Muito ainda deve ser problematizado e explanado, sobretudo, no que toca às possibilidades de construção de representações sociais positivas sobre o negro, uma vez que a sua imagem, representação e subjetividade estão perpassadas por representações sociais prescritivas e coisificantes e tão presentes, atuais e arraigadas em nosso imaginário social.

\section{Referências}

André, M. C. (2007). Psicossociologia e Negritude: breve reflexão sobre o "ser negro" no Brasil. Boletim Academia Paulista de Psicologia, XXVII(2), 87-102.

Bernd, Z. (1987). Negritude e literatura na América Latina. Porto Alegre: Mercado Aberto.

Brasil. (2012). Lei no 12.711, de 29 de agosto de 2012. Recuperado em 13 de janeiro, 2014, de http://www.planalto.gov.br/ccivil_03/_ato2011-2014/2012/lei/l12711.htm.

Brasil. (2014). Lei no 12.990, de 9 de junho de 2014. Recuperado em 23 de junho, 2014, de http://www.planalto.gov.br/ccivil_03/_Ato2011-2014/2014/Lei/L12990.htm.

Cabecinhas, R., \& Amâncio, L. (2003). A naturalização da diferença: Representações sobre raça e grupo étnico. Comunicação apresentada à III Jornada Internacional sobre Representações Sociais, Universidade do Estado do Rio de Janeiro/Maison des Sciences de l'Homme, Rio de Janeiro.

Campante, F. R., Crespo, A. R. V., \& Leite, P. G. P. G. (2004). Desigualdade salarial entre raças no mercado de trabalho urbano brasileiro: Aspectos regionais. Revista Brasileira de Economia, 58(2), 185-210.

Duveen, G. (2004). Introdução: O poder das ideias. In S. Moscovici (Ed.). Representações sociais: Investigação em psicologia social (pp. 7-28). Petrópolis, RJ: Vozes. 
Ferreira, R. F., \& Mattos, R. M. (2007). O afro-brasileiro e o debate sobre o sistema de cotas: Um enfoque psicossocial. Psicologia Ciência e Profissão, 27(1), 46-63.

Freyre, G. (1966). Casa-grande e senzala. Formação da família brasileira sob regime de economia patriarcal (14a ed.). Rio de Janeiro: Livraria José Olympio Editora.

Fry, P., \& Maggie, Y. (2004). Cotas raciais: construindo um país dividido? Econômica: Revista da Pós-Graduação em Economia da UFF, 6(1),153-161.

Fry, P. (2005-2006). Ciência social e política racial no Brasil. Revista da USP, 68(dez./fev.), 180-187.

Fry, P. (2005). A Persistência da raça: ensaios antropológicos sobre o Brasil e a África austral. Rio de Janeiro: Civilização Brasileira.

Guareschi, P. (2011). Pressupostos psicossociais da exclusão: Competitividade e culpabilização. In B. Sawaia. (Org.). As artimanhas da exclusão: Análise psicossocial e ética da desigualdade social (pp.143-157). Petrópolis: Vozes.

Henriques, R. (2001). Desigualdade Racial no Brasil: Evolução das condições de vida na década de 90 . Rio de Janeiro: IPEA.

Jodelet, D. (2001). Representações sociais: um domínio em expansão. In D. Jodelet (Org.). As representações sociais (pp. 17-44). Rio de Janeiro: Editora da UERJ.

Jodelet, D. (1998). A alteridade como produto e processo psicossocial. In A. Arruda (Org.). Representando a alteridade (pp.47-68). Petrópolis, RJ: Vozes.

Jodelet, D. (2005). Loucuras e representações sociais. Petrópolis: Vozes.

Jovchelovitch, S. (1998). Re (des) cobrindo o outro. Para um entendimento da alteridade na Teoria das representações sociais. In A. Arruda (Org.). Representando a alteridade (pp.69-82). Petrópolis, RJ: Vozes.

Lage, N. (2003). Educação e a política de cotas. Observatório da Imprensa, no 215. Recuperado em 22 de setembro, 2013, de http://observatorio.ultimosegundo.ig.com.br/cadernos/cid120320031.htm.

Lima, M. E. O., Neves, P. S. C., \& Silva, P. B. (2014). A implantação de cotas na universidade: paternalismo e ameaça à posição dos grupos dominantes. Rev. Bras. Educ., 19(56).

Maggie, Y. (2005). Política de cotas e o vestibular da UnB ou a marca que cria sociedades divididas. Horizontes Antropológicos, 11(23), 286-291.

Maggie, Y. (2005-2006). Uma nova pedagogia racial? Revista da USP, 68, 112-129.

Maggie, Y. (2006). Racismo e anti-racismo: preconceito, discriminação e os jovens estudantes nas escolas cariocas. Educação e Sociedade, 27(96) - Especial, 739-751.

Maggie, Y., \& Fry, P. (2004). A reserva de vagas para negros nas universidades brasileiras. Estudos Avançados: revista do IEA da USP, 18(50), 67-80.

Martins, E., Santos, A. O., \& Colosso, M. (2013). Relações étnico-raciais e psicologia: publicações em periódicos da SciELO e Lilacs. Psicologia: Teoria e Prática, 15(3), 118-133.

Menin, M. S. S., Shimizu, A. M., Silva, D. J., Cioldi, F. L., \& Buschini, F. (2008) Representações de estudantes universitários sobre alunos cotistas: Confronto de valores. Educação e Pesquisa, 34(2), 255-272.

Moscovici, S. (1978). A representação social da psicanálise. Rio de Janeiro: Zahar Editores.

Moscovici, S. (2007) Representações sociais: Investigações em Psicologia Social. (5a ed.). Petrópolis, RJ: Vozes.

Naiff, D. G. M., Naiff, L. A. M., \& Souza, M. A. (2009). As representações sociais de estudantes universitários a respeito das cotas para negros e pardos nas universidades públicas brasileiras. Estudos e Pesquisas em Psicologia, 9(1), 219-232.

Neves, P. S. C., \& Lima, M. E. O. (2007). Percepções de justiça social e atitudes de estudantes pré-vestibulandos e universitários sobre as cotas para negros e pardos nas universidades públicas. Revista Brasileira de Educação, 12(34).

Paixão, M., \& Carvano, L. M. (Orgs.). (2008). Relatório Anual das desigualdades raciais no Brasil; 2007-2008. Rio de Janeiro: Garamond Universitária. 
Pereira, C., Torres, A. R. R., \& Almeida, S. T. (2003). Um estudo do preconceito na perspectiva das representações sociais: análise da influência de um discurso justificador da discriminação no preconceito racial. Psicologia: Reflexão e Crítica, 16(1), 95-107.

Sacramento, A. N., \& Nascimento, E. R. (2011). Racismo e saúde: representações sociais de mulheres e profissionais sobre o quesito cor/raça. Rev. Esc. Enferm. USP, 45(5), 1142-9.

Santos, A. O., Schucman, L. V., \& Martins, H. V. (2012). Breve histórico do pensamento psicológico brasileiro sobre relações étnico-raciais. Psicologia: Ciência e Profissão, 32(num. esp.), 166-175.

Santos, E. F. (2011a). Representações sociais de estudantes negros: universidade e trabalho. Dissertação de Mestrado, Universidade Federal de São Carlos, São Carlos- SP, Brasil.

Santos, E. F. (2011b). Das margens, escritos negros: relações entre literatura periférica e identidade negra. Projeto de doutorado, Fundação de Amparo à Pesquisa do Estado de São Paulo, Brasil.

Santos, S. A. (2008). O Debate sobre as ações afirmativas para negros e a questão das cotas nas universidades públicas brasileiras: implantando o terror. Anais do VI Congresso Português de Sociologia-Mundos sociais: Saberes e Práticas.

São Paulo. (2013). Lei no 15.939, de 23 de dezembro de 2013. Recuperado em 23 de Junho, 2014 de http://www.jusbrasil.com.br/diarios/68108300/dosp-cidade-26-03-2014-pg-60.

Silva, P. B., \& Silva, P. (2012) Representações sociais de estudantes universitários sobre cotas na universidade. Fractal, Rev. Psicol., 24(3), 525-54.

Soares, S. S. D. (2000). O perfil da discriminação no mercado de trabalho: Homens negros, mulheres brancas e mulheres negras. Brasília: Ipea.

Valentim, J. P. (2013). Que futuro para as representações sociais? Psicologia e Saber Social, 2(2), 158-166. 